\title{
What might the school of 2030 be like? An exercise in social science fiction
}

\author{
Neil Selwyn* \\ Faculty of Education, Monash University, Australia \\ Luci Pangrazio \\ REDI Centre, Deakin University, Australia \\ Selena Nemorin \\ UCL Knowledge Lab, University College London, UK \\ Carlo Perrotta \\ Faculty of Education, Monash University, Australia
}

* Neil Selwyn

Faculty of Education, Monash University, 19 Ancora Imparo Way, Melbourne, VIC 3800, Australia

Neil.selwyn@monash.edu

Neil Selwyn is a Distinguished Research Professor at the Faculty of Education, Monash University. His research and teaching focuses on the place of digital media in everyday life, and the sociology of technology (non)use in educational settings. Neil is the author of, Distrusting Educational Technology, Is Technology Good For Education?, and What Is Digital Sociology?

@Neil_Selwyn

Luci Pangrazio is a Research Fellow in digital literacies at REDI (Research for Educational Impact) in Deakin University. Her research focuses on critical digital literacies, the platformatization and datafication of education. Luci is the author of Young People's Literacies in the Digital Age: Continuities, Conflicts and Contradictions in Practice. @lucipangrazio

Selena Nemorin is a lecturer in sociology of digital technology at the University College London, UCL Knowledge Lab. Selena's research focuses on critical theories of technology, surveillance studies, data/loT ethics, and youth and new media/technologies. Selena is the author of Biosurveillance in New Media Marketing.

@ digiteracy

Carlo Perrotta is a senior lecturer in digital literacies in the Faculty of Education at Monash University. Carlo has published on a variety of topics related to digital technology in education, including the social and political accountability of algorithms in education, the ethical use of video games in schools and socio-material analyses of digital education. @CarloPer 


\title{
What might the school of 2030 be like? An exercise in social science fiction
}

\begin{abstract}
This article addresses the deliberately speculative question of 'What might the school of 2030 be like?', with a specific focus on the influences of digital technologies. The article adopts the methodological approach of 'social science fiction' to explore the ways in which digital technologies might be used in one Australian high school in 2030 (Lakeside), and what this might mean for the people whose lives are enmeshed with these technologies. Through the co-construction of five social science fiction 'vignettes' about life within Lakeside, the article considers the increasing prevalence of dataveillance, digital deskilling, and the deterritorialisation of schooling. The article then goes on to consider changing relationships between time/place, material and coded structures, as well as the increasingly platformized and data-driven nature of schooling in the 2020s. The article ends by considering the ways in which critical scholars can continue to use the methodological approach of social science fiction writing with regards to unpacking the politics of digital education futures.
\end{abstract}




\section{What might the school of 2030 be like? An exercise in social science fiction}

\section{INTRODUCTION}

Academic discussions of education and digital technology tend to be resolutely forward-looking, often focused on exploring the potential of 'new' technology and 'leading edge' innovations. This is an area of educational scholarship that prefers to keep its eye on the near future rather than the immediate present. Oftentimes, mainstream writing and research on education and digital technology is proud to pitch 'what if?' and 'what could?' questions. Reflecting on previous failures and present-day compromises seems much less important than looking toward emerging trends and expected transformations.

Understandably, one of the distinguishing features of critical scholarship of education and technology (for example, as often featured in Learning Media \& Technology) is a reticence to play the same game. Critical work in this area tends to take a deliberately different approach that eschews future-gazing, speculation and forecasting. This writing and research usually strives to develop detailed accounts of 'real life' inequalities, injustices and inconsistences of technology use that have already happened. This approach therefore highlights the immediate realities of education and technology. This preference to think about what has already taken place acknowledges that the future is notoriously tricky to 'predict', and that any talk of possible/preferred futures is highly values-driven and contestable.

Given our usual aversion toward all things 'futuristic' we therefore approach this Special Issue with a fair degree of caution. Nevertheless we have taken this article as an opportunity to temporarily go against type and tackle the tantalizing question of 'What might the school of $\mathbf{2 0 3 0}$ be like?'. In exploring this question, we are adopting a number of explicit assumptions. First, given the theme of this special issue we are primarily grounding these stories in terms of the technological conditions of the school of 2030 as the main lens through which to view difference and change over the next ten years. While touching on issues of population expansion, shifting global economics and increased commercialisation of education, we are not envisaging more radical demographic, environmental and/or economic futures that others are exploring fruitfully elsewhere.

Indeed, the second underpinning assumption of our paper is a focus on the banal and everyday extensions of technological and educational trends that are already emergent and/or beginning to be established in the school systems of many (over)industrialised contexts. Moreover, our relatively quotidian focus corresponds with what Riel Miller (2018) terms 'fatalistic' stories that betray an embedded (albeit begrudging) commitment to ideologies such as market capitalism and neoliberalism. 
As we shall discuss in the later stages of the article, this 'non-radical' approach to futures thinking is most suited to generating thinking that is congruent with ideologically pre-determined futures. As David Hicks and Cathie Holden (1995) suggest, futures thinking of this sort often reflect an implicit feeling that we are living in societies that may well be "in stagnation or decline".

Nevertheless, setting the parameters of our article in this way marks a conscious attempt to produce an everyday, mundane counterpoint to current discourses surrounding educational and technological futures. The everyday realities of education have rarely proven to be spectacular over the past 100 years, so we were interested in imagining what schools might be like ten years from now if things do not somehow turn out to be radically different. In contrast to the over-zealous tone of mainstream discussions of EdTech 'disruptions' and 'transformations', we wanted to consider the ordinary futures of education practice and education provision.

Thinking of the futures of schools and digital technology along ordinary (rather than extraordinary) lines is certainly in keeping with the history of digital technology use in schools to date. First, any school is always a patchwork of new and old resourcing, with any freshly purchased device or system inevitably having to find a place amidst assortments of technology from times gone by. A starting-point for this article, therefore, is the premise that most schools of 2030 will contain a considerable amount of the digital technology that they acquired in 2020 (if not earlier). We speculate that the school of 2030 will be replete with what were once 'new' devices, systems and applications from the late 2010s that have not yet been replaced by state-of-the-art technologies of the late 2020s. For every recently-installed holographic display there is likely to be a 10-year-old plasma screen flickering away around the corner.

Second, we are also starting from the premise that the enduring 'grammars' of late twentieth century schooling will persist for a few decades more. Beneath their digital surfaces, much of what currently takes place in schools reflects long-standing educational structures, processes and customs that endure from long before the digital age. As we write, Australian schools in 2020 continue to prioritize student discipline, achievement, retention and progression. Hierarchies between staff, administrators, students and parents persist much as before. Knowledge remains compartmentalized in curriculum areas and assessed through high-stakes testing. All told, the arrangement and organization of schools in 2020 continues to be centred around long-standing principles of standardization, measurement, order and hierarchy. While it is disingenuous to claim that today's schools have not changed at all since the introduction of classroom computers, a set of very strong reference points have persisted throughout this time, and might well persist for some time longer. Assuming these specific conditions, then, what might the schools of 2030 look like?

\section{SPECULATING ABOUT SCHOOLS AND DIGITAL TECHNOLOGY - 'SOCIAL SCIENCE FICTION'}


The nature of the question 'What might the school of 2030 be like?' invites the telling of stories of some kind. Here, then, we turn to the idea of 'social science fiction'. This might not be a familiar approach within critical studies of education and digital technology, but it fits rather neatly with the terms of our current exercise. Social science fiction involves the telling of 'inexistent' tales "that inspire the sociological imagination" (Gerlach and Hamilton 2003, p.156). This evocation of the sociological imagination is deliberate, echoing $\mathrm{C}$. Wright Mills' firm belief that sociological sensibilities were as much evident in fiction and journalistic writing as in the written output of academic researchers and theorists. Thus social science fiction involves the telling of stories related to key themes and ideas from contemporary sociology and how they might play out in different local contexts and cultures. Writing stories is therefore acknowledged as a valuable mode of thought for the social scientist - "a methodology for grasping the social" (Gerlach and Hamilton 2003, p.168).

Science fiction has always been concerned with exploring the nature of future societies as well as future technologies. Indeed, Donald $\mathrm{F}$. Theall used the term 'social science fiction' in 1975 to describe science fiction writing that drew directly upon ideas from the social sciences. In light of the slow response from academic sociology to the initial rise of digital technology, science fiction was briefly touted during the 1980s and 1990s as providing academics with a much-need sophisticated reading of sociotechnical change. Critical commentators such as Donna Haraway were keen to position their work as 'social SF' (see Gerlach and Hamilton 2003), and the genre of Cyberpunk was plausibly mooted as offering possibly the most insightful and sympathetic take on the digital future of the time (Burrows 1997). Subsequently, it has been reasoned that fictional television series such as 'The Wire' provided exemplary sociological explorations of social inequalities in 2000s' America (Penfold-Mounce et al. 2011), alongside the recent eager reception of writing on the theme of 'economic science fictions' (Davies 2018).

Unlike the writing of The Wire and cyberpunk classics, however, the emphasis of our own writing needs to remain firmly on the side of 'social science' rather than 'fiction'. Of course, social science fiction implies a creative exercise that strives for what Andrew Abbott (2007) terms a 'lyrical sociology' - i.e. writing that can evoke feelings in the minds of readers about a specific social situation. Yet the overall goal of an article such as the one you are now reading is not to produce complete narratives and entertainingly 'full' stories. Instead, our goal is to generate ideas and understandings from a simple vignette or "single image to communicate a mood, an emotional sense of social reality" (Abbot 2007, p.73). This is certainly the thrust of recent experiments elsewhere in 'sociological fiction' (so-fi) - as Ashleigh Watson (2017, p.1) describes it:

"Sociological fiction highlights and illuminates many aspects of social life. It shows the many complicated and confusing relationships that make up our lives - between people, and also between times and places and animals and other things. For me, there is real power in this kind of sociology. Metaphors can unsettle things. The right scene can not only show us how sociological imagination works but also draw us into doing this imagination". 
By taking this approach toward telling stories of education and technology we are positioning ourselves within a couple of distinct bodies of writing. On one hand, is four decades of work in the area of education futures (e.g. David Hicks, Richard Slaughter, Sohail Inayatullah and Ivana Milojević). This has seen the regular writing of speculative fictions and scenario writing on future forms of schooling, higher education and other educational contexts (see Facer 2011). On the other hand, is a recent renaissance of technology-related futures storytelling. Of recent note is Mark Graham and colleagues' collection titled 'How To Run A City Like Amazon and Other Fables' - containing 38 separate near-future scenarios where various digital platform companies are speculated to be running cities and urban infrastructures. As the editors of this collection reason:

"the [speculative fiction] genre is a powerful and engaging medium because it uses extrapolation and speculation to explore possible worlds and to encourage the reader to reflect on how those worlds came into being, how they operate, and how they differ from and reflect our present world. As such, they use the tactics of estrangement (pushing a reader outside of what they comfortably know) and defamiliarization (making the familiar strange) as a way of creating a distancing mirror on society and to offer cognitive spaces to reconsider assumptions, rationales and viewpoints. In our cases, the stories seek to be plausible and consistent given existing technologies, business models, trends, news coverage and academic critique, though sometimes they push the logic, ethos, and the form and use of technology to an extreme to emphasize a point; they are sometimes satirical, sardonic and playful. They are designed to prompt critical thought about contemporary neoliberal urbanism and digital, networked technologies" (Graham et al. 2019, pp.9-11).

Following these lines of inquiry, our own fictions about digital technology and schools of 2030 do not seek to comprehensively tie up all the loose ends, point to key causal links and make bold predictions. Rather than explaining, these are stories that could appear to simply confuse and mystify, suggest rather than tell, imply rather than instruct. Any piece of social science fiction can be seen as a thought-experiment that seeks to explore the forms of social life and social order that might result from impending technological conditions. As hinted at earlier, we have chosen to pitch these speculations largely as mundane extrapolations of current developments rather than imagining brave new worlds. To be clear, these are not objective analyses or predictions - the main objective of these stories is to generate debate. These are a specific set of speculations of what the school of 2030 might be like ... and how it might feel to part of it.

\section{METHOD}

In this article we have approached social science fiction writing as a way for different members of our geographically-dispersed research group to genuinely 'think 
together'. The four authors convened a couple of workshops to reach an agreed understanding of the overall school setting (vignette\#1), and then brainstorm the broad pitch of half-a-dozen stories that we considered interesting and of merit (what eventually turned out as vignettes\#2 through \#5) and some of the likely associated issues. We each then wrote first drafts of our stories.

The writing of each draft followed guidelines adapted from Lackey (1994) and Atkinson (2015), which are provided in tables one and two for anyone interested in engaging in a similar exercise. These first drafts were shared and commented upon by the other members of the research group in a public reading event, which was used as a spur to then rewrite each draft. Over an six-month period we drafted, critiqued and made sense of what we were writing - particularly in terms of how each story related to this Special Issue's focus on "key emerging issues/ trends/ challenges in the area of education and technology for the next 10 years".

Lackey's (1994) guidelines for writing social science fiction provided a useful frame to these activities. From a symbolic interactionist perspective, Lackey encourages writing that explores how definitions and emotions emerge from (and are modified during) interactions with others. Crucially, our own writing took these 'others' to be both human and non-human. In this sense, we strove to produce writing concerned with the social interactions between people and machines in the material and virtual settings that together constitute 'school'. One emerging interest was in writing 'future ethnographic' stories that explore how 'digital education' is produced and embedded in social relationships, and worked out in the practice of people's everyday lives (see Table 2 for Atkinson's guidelines for such writing).

Another important aspect for Lackey (1994, p.170) is the use of "sociological source materials to define the characters, plot, setting, and dialogue". Thus in planning our stories we drew on our position as academic experts in the area of digital technology and education - using our knowledge of theory and empirical literature around educational technology as the starting point of each vignette. Finally, we took care to follow Lackey's (1994, p.168) advice to focus on "life's mundane definitions". Our vignettes all tell stories of unremarkable 'slices of everyday life' - the significance of which lies in their connection to the social science of schools and education. This is not fictional writing of any particular merit - luckily for us, this is not the point of social science fiction. Instead these are stories to help us think critically about the future nature and form of schools and schooling in the digital age.

Table One. Chad Lackey (1994). Guidelines for writing social science fiction

There are three dimensions of social science fiction reality:

- the individual level (thoughts and feelings)

- the social level (interaction)

- the physical level (the setting and the characters' body movements)

There are three characteristics of any story: 
- Writers must focus on the thoughts and feelings of all-important characters and on how each character's thoughts and feelings shape their actions and interactions with others.

- Writers must focus on the interaction between characters, especially important characters, and on how this interaction affects each character's thoughts, feelings, and actions.

- Writers must describe the setting and the characters' movements within the setting, and must explore the effects of the setting on characters thoughts, feelings, and interactions with others.

Table Two. Paul Atkinson (2015). Guidelines for ethnographic writing in the social sciences.

- Everyday life takes place in specific locations and is conducted through material artefacts ... writers investigate the lived spaces, the objects and physical 'stuff' that comprise everyday life;

- Everyday life is local ... occurring in local places and through local cultural resources that are available to social actors;

- Everyday life is dialectical ... there is a reciprocal relationship between people's everyday activities and actions and institutional orders and conventions;

- Everyday life is enacted physically ... writers pay attention to people's physical actions;

- Everyday life is symbolic and rendered meaningful through language ... writers pay attention to speech, narratives, signs and other semiotic forms;

- Everyday life is performed ... as Atkinson puts it, "social life does not 'just happen', it is made to happen" (p.18). Writers detail the performances that surround social actions and social meaning;

- Everyday life unfolds over time ... writers are interested in the rhythms, cycles and temporal flows of social life;

- Everyday life is messy ... writers are interested in the contradictions and tensions of everyday life; the differences between words and deeds; what is planned and what results; what is anticipated and what is actually experienced.

\section{VIGNETTE\#1: INTRODUCING LAKESIDE HIGH SCHOOL}

Lakeside High School caters for 11 to 18 -year-old students. The school is located in the inner-city suburbs of Melbourne - a city of 6.5 million people in the south-east of Australia. While not one of the most prosperous areas of the city, this is nevertheless an affluent residential area. Lakeside is a government-funded, public school, although many of the school services are out-sourced to private contractors including all of the school IT infrastructure and resourcing. Lakeside maintains an enrolment of around 2000 students, 30 fully qualified specialized 'leading' teaching staff (who oversee the planning of courses, and take advanced examination classes) and 120 generalist teaching associates (who oversee the majority of nonexamination classes).

The school was founded in the 1950s, although all of the school buildings have since been replaced and/or upgraded. The school had a major rebuilding phase throughout the 2010s, including a multi-million-dollar high-tech teaching centre. 
Students take a blend of face-to-face classes (facilitated by teaching assistants) and online lessons (which some students access by sitting in learning booths in the school's online learning building, while others opt to access from home).

In terms of technology use, students are required to bring at least one 'learningready' device to school using a high-end smartphone (with keyboard capacity) or an entry-level laptop. The majority of Lakeside's day-to-day business takes place through the Oracle 'school management platform' (a cloud-based platform used by most schools in the area and run by a Google affiliate). This platform is an integral element of school life - the conduit for all school operations. This includes the collation of personal information and other record keeping, communications between school managers, administrators, staff, students and parents. The system is also used for the production and delivery of teaching resources and content. The system is connected to a powerful analytics system (Predict-Ed) and personalized learning system that drives each student's individualized 'adaptive' curriculum provision. Both these systems are plug-ins from Google platform providers and used widely across North America, the UK and elsewhere.

Following the establishment of the P-TECH model in Australia fifteen years previously, Lakeside is officially partnered with a corporate partner (PwC Australia). PwC provide finance, business support and also sponsor the school's students into industry placements and employment opportunities. Otherwise, much of what goes on in the school is steered by state and federal government. In particular, the school follows a state-modified version of the Australian national curriculum. Students take annual national online tests of literacy and numeracy (so-called NAPLAN), and aim toward the end-of-school VCE online examinations before going onto university or employment. As has been the case for as long as anyone can remember, Lakeside is a place that succeeds or fails on the basis of its students doing well and getting through the system.

\section{VIGNETTE\#2: TESTING TIMES}

$<$ Ping $><$ Ping $><$ Ping $>$

The 'URGENT REQUEST TO ATTEND' from the Principal's Office had initially come to Mia's phone on a daily basis. New messages were now being sent every hour or so. After a final morning of ignoring the notifications Mia resigned herself to accepting the calendar invite and heading into Lakeside.

As a fulltime Year 12 student, being physically present on campus was no longer a frequent occurrence. Over the years Mia had increasingly opted for online courses whenever she could. She was now largely accessing online classes from home rather than schlepping into school to sit silently in one of the online learning booths. Her dad had always huffily said that if she was going to work in a call-centre then she should at least be getting paid for it.

Mia couldn't remember ever having spoken directly to the Executive Principal 
during her six years at Lakeside High. Thinking about it, she had probably only had proper facetime with her form tutor a dozen times over the past 12 months.

As a senior year student Mia was in privileged position of being able to pick and choose her modes of learning engagement - which she had eagerly arranged to fit around a couple of part-time jobs and looking after her younger siblings.

Now, as she was knocking on the office door and seeing faces that she had only really interacted with on-screen, Mia suddenly didn't feel so eager.

The Principal got to the point. 'It's pretty simple, Mia. There's absolutely no way that you took that test fairly'.

This wasn't a huge shock. Mia decided that saying nothing might be the best tactic ... for the time being at least.

After a long pause, the Principal felt obliged to break the silence.

'It's not all bad ... the biometrics indicate that it definitely was you that logged onto the test. And we accept that you were present at the laptop during the examination period. The problem is that very little you did in answering the questions seems to fit with your test-taking profile'

'But ... I was in a hurry,' Mia started - 'I rushed stuff ... and I panicked a little ... and I knew at the time that I was doing things in a funny order ... I just had a complete brain fade'.

'If that's the case', the Principal continued, 'then how come you scored 2 whole quartiles more than you have ever done in any comparable examination ... over the past six years? You were way off the dial from your predicted performance. Your eye-tracking was flagging red. There's nothing in the Predict-Ed data to suggest that this was a fair go.

One of Lakeside's learning analytics team jumped in ...

"The system flags up any student who is 35 percent out of synch ... you were approaching 90". He flipped his screen in Mia's general direction to show her a dashboard. The lack of green or yellow indicators told her all she needed to know.

"Plus you've not been logging into Oracle at all regularly over the past term. There's no sign that you've been engaging over the last quarter ... or the quarter before that".

[Silence]

Mia's form tutor tried to strike a more conciliatory tone: 'We're not sure what you've done here Mia, but this has to go down on your VCE profile as a fraudulent attempt. 
You will get another go next semester but at the moment ..."

Mia tried to interrupt for one final excuse.

"But I've been cramming with an online group in the States. They coached me to try something different for these exams ... it's not what it looks"

[More silence]

"Sorry Mia", the principal said. "You know how tight the system is. Any irregularities - especially with external examinations - are taken very seriously. All of the key data points are flagging malpractice ... so there's nothing else we can do. Your access to the school platform will be suspended for 60 working days. After that you can take a re-test".

He corrected himself, "... a supervised re-test”.

Mia got on the bus in a hurry. She didn't have time to be pissed off as she was on the late afternoon shift at Macca's.

She did know that this was going to come back to bite her on the arse further on down the track. Although Federal law meant that all juvenile data is wiped on your $18^{\text {th }}$ birthday, getting tagged MAL even for the next 12 months was going to screw up her uni applications.

It might even be worth putting those that off for a year or two. There was no way she could keep her parents from being notified. Being caught trying to cheat the school's comms system would be a misdemeanour too far

\section{VIGNETTE\#3: GOING OFF SCRIPT}

There was only 15 minutes until session one started, but first year teacher Laura was still waiting for the class instructions (aka 'the script') to download onto her tablet. She tapped her fingers impatiently on the desk. The download time was still clocking five minutes remaining ... was the network down? Her anxiety grew when she thought about the Year 7 class that was waiting for her at the other end of the download...

This group had been pretty unmotivated all year by now in term 3 they were well and truly over English. So much for 'inspiring young minds'! How naïve she was to think she could pass her passion for writing onto these students. At 12 and 13 years old they were far more cluey about how the education system worked than she did. Any piece of actual writing was for getting a grade, not exploring, experimenting and making meaning of the world. If only Laura's English professor at university could see her now.

An unfamiliar beep rumbled from her device. She looked down, the screen was 
blank ... no download, no script. Panic set in as Laura realised she would have to wing it. How could she know which students were present? What information should she deliver and to which students? What would she tell her supervisor at the end of the class? Marg Daly, the senior leading teacher she reported to at the end of each class, would not be happy to hear that they had achieved anything less than 15 of her 30 learning outcomes intended for the class.

Thinking back on her first year of teaching, Laura was surprised by how quickly she had become dependent on the Oracle platform. She was one of the privileged few who was employed as one of the school's specialized 'leading' teaching staff. Yet within a month of starting the job, she had stopped wondering how she could make difference to any student or lesson that she was responsible for. All her performance indicators, reporting of students, content, even pedagogical strategies were based on Oracle, so what was the point in going off script?

Given all the student data it had, Oracle knew her students better than she did. Every lesson it organised the class into five groups - Band 1, Band 2, Band 3, Band 4 and Band 5 - and each lesson was structured around five interwoven 'scripts' appropriate for their capabilities. When Laura had taken her first job, she had imagined herself planning classes and marking papers late into the night, but actually this was completely not how it was. Oracle took care of most of Laura's planning and assessment. She had become bored with her own classes, and her students could sense it.

Second bell...session one was now underway and Laura was still in the teacher's lounge staring at her still-buffering device. Grabbing that term's set text ('Lord of the Flies') she flew out the door and headed toward the classroom. She'll just have to think of something on the spot. 'I can do it...' she told herself. She remembered back to her first year undergraduate English subject, "Reading as Social Practice". 'That's what I'll do - reading circles'. Instead of the five capacity bands, students would just have to work in mixed groups. Laura shuddered to think what might happen what might happen when the Band 1 kids tried to work with the Band $5 \mathrm{~s}$, but she had little choice...

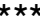

'We're supposed to do what, Miss? Move the tables? Does Ms. Daly know?'

'Actually forget the tables', Laura replied, with an authority that surprised even herself, 'Push them to the side of the classroom. Today we'll sit on the floor in the reading circles I have allocated you to.'

A hush fell over the room. The students looked at each other, unsure whether this was a joke. Some looked up to the cameras at the front of the classroom that provided a livestream of their classes onto Oracle, so parents and guardians could check in on 'any lesson at any time'. Others looked nervously to the glass-fronted 
hallway where Ms Daly would often stand peering in during the lesson.

'Well, get on with it!' Laura commanded.

Laura was so busy moving between the groups and discussing the chapter that she hadn't noticed the time. There was only five minutes left of the class! She hadn't marked her make-shift roll, she hadn't ticked off the learning activities, she had not even put the learning intentions onto the screens around the room.

The classroom looked like it had been ransacked. Tables were bunched up around the perimeter, chairs were stacked one upon the other, some had fallen over, and students were sitting, lying or even standing around chatting in their reading circles.

But the students were engaged with the book in a way that Laura had not seen all year. Sure, some of them were staring absent-mindedly at the ceiling as per usual. But Manus, a student that last lesson Oracle had labelled a 'Band 4', was gesticulating emphatically with book in hand, describing a section of the story in great detail to Soraya and Isabelle, both 'Band 1'. Meanwhile, Lin, the quietest student in the class, held her group's attention as she explained the real reason for Jack and Ralph's argument in chapter three. It was amazing ... they appeared to be learning.

A sharp tapping interrupted her moment of rapture. Marg Daly was standing at the classroom door, her device in hand. As she held her screen up to the window the words 'CLASS 7EF' were flashing alarmingly in red. Laura knew now the Curriculum and Assessment Authority would have been notified of her 'contract breach'. The students looked anxiously to Laura and then back to Marg and then up to the camera, which was flashing in time with Marg's device.

Laura's lesson was over.

\section{VIGNETTE\#4: DISTANT EDUCATION}

The phone alarm goes off at 07:30 with the usual playlist. Adam has a playlist for every occasion, but the last time he actually picked a song was nearly a year ago. The streaming service automatically adds and removes tracks. His music tastes, according to the service, are those of an average male teenager in an Englishspeaking country. Sometimes he thinks he should be offended. Truth is he isn't too bothered...

The air in the tiny bedroom is stale. Adam opens the window and he is hit by the heat and humidity coming from outside. "This doesn't help much" he thinks. $\mathrm{He}$ leaves the room. On his way out he kicks (not too hard) the body lying in the other bed and utters a friendly insult. The body sleepily mutters something unintelligible, turns to the other side and carries on dozing. That's Mohammed, Adam's older 
brother. He finished his studies last year and since then he's been on and off work ever since. Today he is not going anywhere and he probably won't get out of bed for a good few hours more.

Adam has one of his record-breaking 30 second showers in order not to trigger off the water meter. He walks down the stairs and into the kitchen. He gives his mum the usual good morning kiss. She asks if he's ready for school.

Next month, Adam will know his provisional VET score: his ticket to a Business Information Systems BA at Melbourne's Federation University and an internship with PwC. The uni course is being sponsored by two IT corporations with offices in Melbourne's CBD. Adam has his sights firmly set on one of these.

\section{$* * *$}

After a 45-minute bus ride, Adam is at the Lakeside buildings. As he enters the dusty sliding-doors, the facial recognition sensors silently alter his profile to 'on-site'. In the public area his gaze meets that of another student who he has sometimes found himself next in line to. Nobody really knows anyone very well around here. He thinks of something to say to them... but time is scarce. Better head and grab a decent booth!

Adam sits down, dons the noise-cancelling headphones and logs into his personal learning profile. Adam's entire student life over the past two years flashes before his eyes as the dashboard is dynamically assembled. All his units, including the electives, are based on the employment needs identified by Lakeside learning design specialists and his education advisor from $\mathrm{PwC}$. Things can get really dull at times, but the prospect of a streamlined pathway to a degree, plus the rarefied possibility of an actual job, make everything more bearable. Adam just hopes he won't end up like his brother...

The first session of the day begins with a recorded video lesson - the school makes a few of these with its resident leading teachers, but they are nowhere near as slick as the "learning segments" it also buys-in from a digital education supplier in the US.

A few minutes in, the screen goes blank. Adam's machine shuts down abruptly. Power shortage.

Adam is furious. "SHIT! They said on the news we were done with these!" Students begin to emerge from their booths wearing the same frustrated expressions. Adam catches sight again of his line-up buddy ... Everybody walks out in the street. Nothing to do here until the power is back, which could take the whole day.

$* * *$

A few students gather by the front door, under the big sign that says "Lakeside School Malaysia: Personalised Learning Centre". Somebody is complaining about the delays these brown-outs will cause to their courses and their student visa applications. Electricity shortages have become more frequent since a new Alibaba 
Data Centre opened in Cyberjaya. A huge amount of power is needed to cool down the centre and Selangor's regional grid can hardly cope.

As it becomes clear that the day is over, students begin to file out of the atrium oneby-one. Adam slowly walks away. He looks around if he can see a familiar face for the third time that day - but no such luck. He puts his earbuds in and heads for the bus stop.

\section{VIGNETTE\#5: MACHINES WILL WATCH US LEARN}

High school wasn't always like this. At least that's what my dad tells me. Teachers have always been disciplining students, but back in the day there were no machines watching continuously to keep kids in line. Now, the intelligent behaviour management system is in full effect. Every thirty seconds it scans all the classrooms, corridors and even bathrooms. Its logging what you do, picking up your tag. Even if you've hacked your tag it scans your eyes, your face. All that data gets stored and cross-checked to your profile. Every good action scores us a merit point or more depending on what we do. Every bad action does the opposite. It is all about developing your 'character'. Creepy, is what my dad would say, but he's one of the few parents who feel that way. Everyone else thinks it is normal.

Developing our 'character' has been drilled into us from the minute we started primary school. I was four years old when I sat through my first assembly where the principal droned on and on about the six pillars: trustworthiness, respect, responsibility, fairness, caring, and citizenship. You've got to have 'High Grades, High Morals'.

When these reminders fail and when we forget to behave, machines step in to give us a 'nudge'. For example, there are loads of cameras sitting just below the ceilings of all the classrooms. These track six main things: reading, writing, hand-raising, standing up, if we're listening to the teacher, or looking 'off-task'. You wouldn't know they're running apart from the red-light pulsing in the eye of the lens. Every few seconds they scan the classroom, watching our faces for emotions: happy, sad, afraid, bored, angry ...

Our teachers made a point of telling us about the cameras at the beginning of the school year to deter us from acting up. Sometimes they tell us what emotional 'state' we are showing up on the system as and challenge us to do something about it. You can usually fake the machine into flagging you green. My mate Jeremy reckons it's all a scam, that the cameras aren't plugged into anything, but he's wrong. I've been into the IT room and seen it all for myself.

It's in the important NAPLAN standardised test classes that things begin to get serious. These are where you usually have to wear the wristbands. The instant the system flags you as 'Off Task' you get a little electric shock through the band. Sometimes it feels like a tiny tingling that you don't real notice. Other times it is like having a pin prick you which can sting for ages. Apparently, the bands take our 
biometric measurements, and are better at working out how engaged we are than the cameras. The less engaged you are, the more tingly the shock.

It can all get a bit unfair. My dad was called into the school once because the system identified me as 'Angry'. The student behaviour counsellor flagged me 'Red', so a parent meeting was scheduled. But that happened right after my dog had died. He was my best friend and I was sad, but the system had profiled me as angry because I was frowning instead of crying. First my dad couldn't work out what was going on, but he soon got pissed off when he realised the Head of Analytics wasn't really listening to anything he was saying.

"With respect, Mrs Bradshaw," said my dad. "Machines makes mistakes."

"I understand your concerns but this system is never wrong," she replied with a look of certainty. "It is tested and updated more regularly than most. The deep learning processes that underpin the mechanics have proven $100 \%$ reliable."

"But you seem to be placing more faith in the computer than in what my daughter is telling you!"

"Mr Margolis," she smiled. "Students don't always know what they are feeling. And even if they did, they are not always able to articulate it. Besides, the data assists teachers in being better teachers and students to better perform. That's what matters most, don't you think?".

She tilted her laptop toward my dad and invited him to look closely at the colourful graphs on the screen. "You see the data viz ... this is how the technology helps teachers optimise student engagement. It only flags red if there is something seriously wrong."

"But these graphs are only guessing what a student might be and might do, not what a student actually is." My dad was clearly upset. "Where's the humanity in all of this?"

Mrs Bradshaw let out a condescending 'Hmmm'. My dad gripped the side of his chair more tightly. His knuckles turned white. I wanted to say something, but he caught my eye and gave me a warning look. I slunk back into my chair in silence.

"Mr Margolis, student and teacher performance at Lakeside have increased significantly since we started using this system." She dipped her laptop screen and leaned over her desk, staring at my dad with a knowing look. "This software has been in development for over a decade. It's using deep learning ... it's what they use in PwC. You must have faith in the technology. It's the best solution."

"Faith?! Can you at least tell me how it works?"

Mrs Bradshaw crossed her arms and clenched her jaw, seeming a little flustered with my dad's question. She slowly began to put together an explanation. "These 
machines evolve continuously ... they're very complex ... even the programmers no longer know for sure what the system thinking and how it makes a judgment ... What I do know, however, is that it works. And that is definitely all that matters to us..."

The rest of the conversation was a blur. I knew that as much as he would try, my dad could not change the way things were. When the meeting was over, l'd be sent back to the classroom, go through the motions of being 'engaged', 'on-track' and much less 'angry'. Rinse and repeat. This is the school of today. Some say technology has saved us. I say it has made things worse.

\section{DISCUSSION}

These brief stories evoke a collective sense of the nature and form of the school of 2030, as well as how it might feel to live, work and learn within such a setting. Gaining insights into such feelings is perhaps the most interesting aspect of the storytelling process. Beyond the question of what broad types of devices and systems might be used in 2030, are what are more interesting questions (for us) of what this might mean for people whose lives are enmeshed with these technologies. For example, who can be sure as we write in 2020 how Al-driven automation or the 'Internet Of Things' will eventually come to shape people's thoughts and feelings, social relationships, interactions or body movements? Thus, the main benefit of developing these fictional narratives about 'Lakeside of 2030' has been to push ourselves to consider the social realities of the digital conditions that we have chosen to focus on. Although we are clearly not professional fiction writers producing sparkling prose and gripping plotlines, some important ideas and concerns emerge nonetheless:

\section{i) Schooling as a never-ending 'pursuit'}

First, is the idea that school is now something that needs to be engaged with on a continuous basis, regardless of time, space or place. All our vignettes hint at some significant reconfigurations of place, space and time through the use of digital technologies. Of course, there continues to be a 'place' that is Lakeside - not least the buildings on the site of the original 1950s campus in Melbourne. As described in 'Distant Education', there is also another physical place a few thousands of miles away which has recently been constructed to profit from the export of 'authentic' Australian education abroad (albeit replicated at a much-reduced cost and lowerfidelity). Yet despite the endurance of its physical buildings and classrooms, our stories also give a sense of how the 'space' of Lakeside is infinitely expanded through the use of digital technologies. For example, older students such as Mia can opt to take classes online and off-campus. Elsewhere, the business plan behind the school's Malaysian 'international' program allows for extending this service to other territories and markets where there might be sufficient demand. This expansionist mind-set also relates to the times of day that Lakeside could be described as operating. Online provision has done away with any commonly 
understood distinction between 'school time' and 'leisure time', the 'school day' and a 'day off'. The Lakeside experience is one that is flexible, nomadic, more precarious and perhaps a little less predictable than before.

In many ways these shifts simply reflect the continuing correspondence between the school and (late)capitalist modes of production and work. There are increasingly few working practices in the 2020 s that rely on the need for co-location and cooccurrence. Like most aspects of post-Fordist institutions, an individual is compelled by Lakeside to engage with their schooling as a project of constantly striving to be productive, regardless of time and space. Schooling has therefore become what Negri (2008) terms a form of never-ending 'pursuit-race'. Our stories point to the way in which being constantly "on" in this way is a doubled-edged sword. In theory, there are more opportunities for individual self-determination. Some students and teachers undoubtedly benefit from the fluid and 'free-floating' nature of how they engage with school - benefiting from the lack of ties, blurred demarcations of time/space, and opportunities to make their own connections and pathways through the school system. Yet, for others the same conditions are clearly leading to feelings of being un-moored and lacking roots, routines and boundaries.

\section{ii) School as code/space}

Second, is the idea of Lakeside as an assortment of material spaces that are entwined with (and increasingly defined by) code. All of our stories illustrate ways in which Lakeside is configured as what Rob Kitchin terms 'code/space' - that is, a setting where physical spaces and software code "become mutually constituted ... produced through one another" (Kitchin and Dodge 2011, p.16). In one sense, then, our stories describe ways that material aspects of school can shape the nature of the 'technology' that is encountered within Lakeside. Energy supplies are intermittent, and fraying cables and aging infrastructures hinder the promise of being 'always on'. Conversely, our stories also point to ways in which coded systems deployed within Lakeside can act as organizing mechanisms for the staff and students using them, setting the parameters of what can (and what cannot) be done within the face-to-face environment of school. For example, a student wanting to be recognized as physically 'present' has to walk deliberately into a zone where they will trigger the facial recognition software. It is not simply enough for students such as Mia and Adam to actually 'be' at their school. Most important is that they are profiled in code as having done so.

Such examples illustrate how software/code has become a primary mode of how power is exercised in school. Lakeside is an institution that operates according to a logic of control that is ultimately reduced to what can be represented digitally. Thus an assemblage of sensors, systems, personal devices and applications assumes an authoritative role - rendering what goes on within the school as "legible, recordable, and knowable via particular numeric and linguistic constructions" (Franklin 2015, p.xix). Indeed, many of the social processes described in our stories are infused with assumptions of digitally-based efficiency, precision and accuracy. Entities and events are deemed to be knowable and controllable when converted into digital 
forms. The administration and organization of individuals, classrooms and campuses is driven by a logic of control that stems from a confidence and certainty of everything "being on the system".

While many staff, students and parents remain cognizant of the 'real life' frailties and falsehoods of any such certainty, the day-to-day operations of the school nevertheless are sustained by a pretence of digital 'knowing'. For better or worse, Lakeside remains reliant on dashboards and profiles, modelling, analytics and datadriven predictions. Of course, this is not to say that the school is any more alert or responsive in 2030 than it might have been ten (or even fifty) years previously. While a wealth of digital data is being continuously amassed, very few people have time to properly scrutinize this wealth of information (and when they do they are often stymied by gaps, omissions and incompatibilities). Through digital technology everything is now considered knowable, although still relatively little is known.

\section{iii) The platformized school}

These issues also relate to our third observation of Lakeside being a 'platformatized' institution. Indeed, most operational aspects of Lakeside remain beholden to its school management platform (Oracle). Our vignettes illustrate how Oracle (and the other platforms it connects with) is integral to the long-term organisation and planning of the school, as well as a key determinant of day-to-day decisions within every classroom. Teacher Laura in the story 'Going off Script' has all but given up on designing her own lessons, acknowledging that the teaching application built into Oracle 'knows her students better than she does'. Expert judgements are taken out of teachers' hands as they struggle to compete with a seemingly comprehensive collection of data on every student in the school. Indeed, Oracle certainly allows the school to save money on fully qualified teachers like Laura, and instead employ generalist assistants to steward the classroom decisions that the software makes.

In many ways, such arrangements simply reflect the rise of the 'platform' as the dominant infrastructural and economic model of the 2020s (Helmond 2015). On one hand, a platform such as Oracle is a powerful computational force - an 'intermediary' architecture that meshes with other applications. This is illustrated in the ways that Oracle connects and interacts seamlessly with 'non-school' platforms. For example, through Oracle, the commercial music streaming service that accompanies Adam's daily routines in the story 'Distant Education' is an equally prominent part of his 'school' experience as the automated messages from the Principal's office. On the other hand, the idea of 'Oracle' is also a powerful discursive force (Gillespie 2010), prompting students, staff and parents to quickly come to understand the platform as the primary 'space' where teaching and learning takes place. In this sense, students can 'feel' as if they are studying at Lakeside right until the moment they log-off from their isolation booth in Malaysia or their bedroom in Melbourne.

\section{iv) The datafied school}


Fourth, then, is the almost complete dependency of Lakeside upon data generated by digital technology. For example, as soon as any action is mediated through Oracle, fine-grained information is available for scrutiny. Usually this data-processing of actions and behaviours is framed in terms of making better sense of 'learning' - in particular, the profiling, predicting, and positioning of individual students in terms of their learning 'engagement' and 'outcomes'. As van Dijck and Poell (2018, p.579) put it, 'learning processes are translated into data processes and turned into tracking systems that continuously relate individual progress to standardised performance'. Of course, this ongoing generation of data is not solely concerned with personalizing learning or standardizing performance, but also exploiting coded-based power asymmetries in order to discipline students and teachers. In the story 'Machines Will Watch Us Learn', the consequences of personal data collection (via tags and facial scanning) take a decidedly intrusive turn as students caught 'off task' are nudged and prodded into action. For the most part, students and teachers in these stories have adjusted to these data-driven prompts - internalizing and reproducing the directive grammar of school technologies, with only sporadic occurrences pricking their critical consciousness.

Our stories also highlight the vast scope of the data being generated - not least technologies designed "to data-mine the embodied, behavioural and emotional aspects of learning" (Williamson 2017, p.124). One of the core components of Lakeside is what Williamson describes as 'ComPsy' methods - that is, the blending of computational and psychological techniques to render individuals as governable subjects through various 'non-cognitive' indicators. Lakeside is not out-of-theordinary in making use of such technology. Indeed, the school's use of these technologies simply reflects the broader adoption of 'affective computing' techniques across society. The 2020 s has seen a rise of facial detection, body gestures, galvanic skin response and other biometric techniques to detect people's moods, emotions and intentions, as well as measurements of neurological activity and 'brain data' as a basis for guiding behaviour change.

While these technologies are broadly welcomed by educators for potentially opening up the 'Black Box' of learning, our stories point to a number of attendant problems and dilemmas. For example, Lakeside's techniques raise obvious concerns over issues of 'mental privacy' - not least the constant prospect of students having what were once private emotions and inner-psychological traits now made a focus of public scrutiny. Another concern is the ways in which these technologies steadily distract attention away from the social aspects of schooling. As Williamson (2017, p.131) points out, these are systems that reframe educational issues in terms of "psychological deficit[s] in the individual, rather than focusing on social, environmental or material courses of emotional problems".

\section{v) Affective elements of the digital school}

Following on from these latter points, our stories also touch upon the affective complexities of the digitally-mediated school. As stated at the beginning of the article, a key intention of our social fiction writing is to consider how it might feel to be 
part of the digital school of 2030. As evident in all the vignettes, people's engagements with Lakeside were certainly being shaped by a range of digitallymediated emotions, moods and feelings. All our vignettes give a sense of the exhaustion, excitement, boredom, thrills, discomfort and relief associated with digitally-driven schooling. In one sense, then, these stories describe ways in which technologies are continually shaping the emotions, moods and feelings of students and staff. This includes the ways in which digital technologies play an increasingly key part in the production of student and teacher subjectivities. For example, learning analytics tells us that Mia is a supposedly untrustworthy student, the behaviour management system tells Mr. Margolis that his daughter is emotionally unstable. As such, digital technology is not simply supporting the transmission or exchange of information between staff and students. Instead, these technologies are moulding peoples' feelings, perceptions and moods, and therefore functioning as a means of managing and controlling people and their bodies. As Deleuze described it, such manipulation of affect is a key way in which free-floating modulated 'forms' of power now function (see Poster and Savat 2009).

In another sense, our stories also highlight instances where machine-based logics do not work to shape people's moods, emotions and actions, but rather initiate and/or intensify ruptures, frictions and non-compliant responses. This reflects Hassan and Sutherland's (2017) argument that tensions inevitably arise when imprecise, messy humans are compelled to work under precise, neat digital conditions. Hassan and Sutherland point to the increasing 'digital intolerance' of computer technologies and online systems for the essential qualities that make us human. These include the human capacity to thrive on not knowing, being imprecise, to bluff things and assume a 'that'll do' mentality. In contrast, the technologies underpinning Lakeside are based on the precision and certainty of something being either a 'zero' or a 'one', a green cell or a red cell. Problems inevitably arise when students and staff feel unable to harmonize with such hard-and-fast logic.

\section{vi) Agency and resistance in the school of 2030?}

Finally, then, are questions over what these stories tell us about issues of independence and self-determination of people living and working within Lakeside. Schools have always been regulated institutions, yet the Australian education system of 2030 comes across as tightly standardized, benchmarked and centralized - all characteristics that are supported by the digital systems being used within schools such as Lakeside. Rather than facilitating open and fluid forms of learning and communication, students, teachers and parents are 'locked in' (Lanier 2010 ) to these technical systems and their ways of categorizing individuals and orchestrating interactions. Thus school technologies function in ways that leave little room for affective, embodied and spontaneous action. Instead, linear notions of progression prevail, and human 'agency' is channelled into productive engagement with digital technologies (Brown, Rappert \& Webster, 2016). In this manner, promises of flexibility and personalization do not correspond to any genuine sense of individual autonomy or agency. At best, our stories describe students' and teachers' technology-based agency being framed in terms of deferred 
terms of progression through expected processes and official trajectories. People are free to choose what they do, as long as what they do contributes to passing exams, securing jobs or making sure that the class is taught.

That said, all our stories contain fleeting glimpses of gaps and cracks in this façade, where some students and staff might have opportunities to resist, push back and work around the digital structures and boundaries implicit in their engagements with school. Indeed, each story is built around moments in which some kind of localized and temporary disruption arises in the daily pattern of events, and opportunities to resist and challenge arise. Individuals such as Mia and Laura are able to recognize problems and power relations and, sometimes, defy or resist the predicted path or pattern of behaviour. Such episodes should remind us that digital education can be distinctly different in nature and form when carried out with the interests of students and teachers genuinely at the centre.

\section{CONCLUSIONS}

As these conceptual 'connections' imply, the main outcomes of our particular approach to social science fiction has been to tell us more about the present. These are not planned futures that we can work toward achieving or avoiding. Instead, in Riel Miller's (2018) terms, our stories 'use-the-future' as a means of opening up thinking about the present. Everything just outlined illustrates what we consider is possible to imagine about technology-laden schooling at present. Indeed, this journal has recently outlined various manifestations of already-existing developments in technology-based schooling that embody the issues raised by our stories (e.g. McStay 2020, Andrejevic \& Selwyn 2020, Manolev et al. 2019). As such, our stories draw attention to already existing issues that need to be foregrounded in more detail when talking about current educational technology arrangements. Our stories also draw attention to the sorts of trajectories and resistances that might also be encouraged.

In this sense, we hope that this article demonstrates how the process of telling stories about the futures of digital education can be a highly generative exercise. There is certainly merit in continuing to write as many different stories about the future of schools as possible. This chimes with Nick Montfort's contention that the digital future is something that is constructed through the prevailing narratives that are told about it. As Montfort (2018, p.xii) reasons: 'we can't just think about how to view [the future] - we need to write it. The future is not something to be predicted, but to be made'. In this sense, it is well worth other scholars putting forward alternative ideas and counter-arguments in a collective effort to capture the narrative and perhaps re-set prevailing agendas for the education of the future.

To reiterate, then, our intention in this paper is to be provocative rather than prophetic. As such, writing stories such as those in this article perhaps constitute a necessary first-step in reorienting collective understandings of digital education as part of complex systems without any obvious 'solution' or neat 'way forward'. Indeed, any of the 'problems' that we might consider are raised by the scenarios imagined in 
this article are not issues that can be simply recognized and acted upon by governments and states, or else addressed by adjusting the priorities and 'social responsibilities' of commercial actors. The complex realities of the issues implicit in our vignettes exceed the late twentieth century social-scientific notions of agency and structure, or the governance of social forces by nations and societies (Urry 2016). On the contrary, these are social developments that are fundamentally nonlinear, uncertain, multi-factorial and emergent in nature. As such, these are not issues that can be planned or regulated 'against' by any central authority. Instead, confronting and reconstituting these digital education futures would require the distributed efforts of loosely 'coordinated' multiple agencies around various visions of social futures (ibid.).

This, then, brings us back to where our article began - that is, considering the value in constructing social (science) fictions. As we have argued, any 'coordinated' efforts for change will first require broadly shared understandings of common issues, common concerns and commonly-agreed ways forward. Of course, our use of social science fictions sits alongside a range of established futures methods - such as strategic foresight methods, horizon-scanning, scenario building, backcasting and others (see Slaughter 1996; Wilkinson 2016). As part of this wider tradition, then, telling stories can be a useful first step in mobilizing and unifying some sort of consensus over ways in which we might attempt to shape the future. There is clearly merit in working out key issues, ideas and concerns through writing, reading and thinking 'out loud' in ways that are explicitly speculative and fictional. As the five vignettes in this article illustrate, social fiction is a ready means of "the sharing of concepts through analogy, through contextualising ideas within a story" (SylvesterBradley 2018, n.p).

The field of critical educational technology scholarship would therefore benefit from the further writing of such 'social fictions' that seek to develop alternate visions for more equitable futures (especially contrasting stories that are more optimistic and/or less mundane than our's). To take up the challenge of social fiction practitioners such as Cadwell Turnbull, what critical issues and ideas about digital technology do we feel need to 'germinate' within public and policy understandings about education? The more stories that are written then the more chance there is for "pinpointing where we agree can lead to mobilisation on those issues" (cited in Sylvester-Bradley 2018 , n.p.). The futures of digital education in 2030 are certainly up for debate, and therefore require us to exercise our fictional imaginations. We hope that the storytelling can continue. 


\section{REFERENCES}

Abbott, A. (2007). Against narrative: a preface to lyrical sociology. Sociological Theory, 25(1): 67-99.

Andrejevic, M. and Selwyn,N. (2020). Facial recognition technology in schools: critical questions and concerns. Learning Media and Technology

Atkinson, P. (2015) For ethnography. London, Sage

Brown, N., Rappert, B., Webster, A. (2016). Introducing contested futures. In N. Brown, Rappert, B., Webster, A. (Ed.), Contested Futures. London, Routledge

Burrows, R. (1997) Virtual culture, urban social polarisation and social science fiction. in Loader, B. (ed.). The governance of cyberspace, London, Routledge, (pp. 38-45)

Facer, K. (2011). Learning futures. London, Routledge

Gerlach, N, and Hamilton, S. (2003). A history of social science fiction. Science Fiction Studies, 30(2):161- 173

Gillespie, T. (2010). The politics of 'platforms'. New Media \& Society, 12(3): 347-364.

Graham, M., Kitchin, R., Mattern, S. and Shaw, J. (2019). How to run a city like Amazon. in Graham, M., Kitchin, R., Mattern, S. and Shaw, J. (eds). 'How to run a city like Amazon and other fables' Oxford, Meatspace Press

Hassan, R. and Sutherland, T. (2017). Philosophy of media. London, Routledge.

Helmond, A. (2015). The platformization of the web. Social Media+ Society, 1(2), 2056305115603080.

Hicks, D. and Holden, C. (1995). Exploring the future: a missing dimension in environmental education. Environmental Education Research, 1(2):185-193

Kitchin, R. and Dodge, M. (2011). Code/space. Cambridge MA, MIT Press

Lackey, C. (1994) Social science fiction. Teaching Sociology, 22(2): 166-173

Lanier, J. (2010). You are not a gadget. New York, Alfred A. Knopf.

Manolev, J., Sullivan, A. and Slee, R. (2019). The datafication of discipline: ClassDojo, surveillance and a performative classroom culture. Learning, Media and Technology, 44(1):36-51

McStay, A. (2020). Emotional Al and EdTech: serving the public good? Learning Media and Technology

Miller, R. (2018). Sensing and making-sense of Futures Literacy: towards a Futures Literacy Framework. in Transforming the Future. (pp. 39-74). London, Routledge.

Montfort, N. (2017). The future. Cambridge MA, MIT Press.

Negri, A. (2008). The labor of the multitude and the fabric of biopolitics. Mediations 23(2):8-25.

Penfold-Mounce, R., Beer, D. and Burrows, R. (2011) The Wire as social sciencefiction? Sociology, 45(1):152-167

Poster, M. and Savat, D. (2009). Deleuze and new technology. Edinburgh, Edinburgh University Press.

Slaughter, R. (1996). Futures studies: From individual to social capacity. Futures, 28(8), 751-762.

Sylvester-Bradley, O (2018). Cadwell Turnbull on social fiction and the collaborative narrative. Coop News, June $14^{\text {th }}$, www.thenews.coop/129406/topic/democracy/cadwell-turnbull-social-fictioncollaborative-narrative/

Urry, J. (2016). What is the future?. Cambridge, Polity 
van Dijck, J. and Poell, T. (2018). Social media platforms and education. in J. Burgess, A. Marwick and T. Poell (Eds.) The SAGE handbook of social media. (pp. 579-591). London: SAGE reference.

Watson, A. (2017) Editorial. So-Fi Zine, 2, p.1 https://sofizine.wordpress.com Wilkinson, A. (2016). Using strategic foresight methods to anticipate and prepare for the jobs-scarce economy. European Journal of Futures Research, 4(1):12 Williamson, B. (2017). Big data in education. London, Sage. 